\title{
AVALIAÇÃO DO MODELO WRF EM RELAÇÃO À TEMPERATURA DO AR E PRESSÃO ATMOSFÉRICA DEVIDO À PASSAGEM DE UMA FRENTE FRIA SOBRE A ILHA DECEPTION, ANTÁRTICA
}

\author{
Nélia Kainara R. Cardoso ${ }^{1, *}$, Ronald B. Souza ${ }^{1}$, Alcimoni Comin ${ }^{2}$ \\ 1- CRS-INPE, 2- Universidade Federal de Santa Maria; Santa Maria, RS, Brasil \\ *n.kainararodrigues@gmail.com
}

\section{RESUMO}

Foi verificado que as interações físicas modelo WRF (Weather Research and Forecasting) podem ser comparadas com os dados coletados na Ilha Deception para permitir aprimoramentos das simulações. Neste trabalho, foi feito a análise de duas variáveis meteorológicas (temperatura do ar e pressão atmosférica) em situações pós e pré-frontal. Em relação a essas variáveis estudadas, observou-se que o WRF mostrou um melhor desempenho para a pressão atmosférica, pois esta depende dos padrões meteorológicos de grande escala.

\begin{abstract}
It was found that the physical interactions of the WRF model (Weather Research and Forecasting) can be compared with data collected at Deception Island, enhancements to allow simulations. This work was done to examine two meteorological variables (air temperature and atmospheric pressure) in post and pre-frontal. With respect to these variables it was observed that the WRF showed a better performance to atmospheric pressure, as this depends on the large-scale weather patterns.
\end{abstract}

\section{INTRODUÇÃO}

O aperfeiçoamento de modelos através das simulações é um desafio para compreender os fenômenos meteorológicos, um destes modelos é o WRF que será estudado neste trabalho. A saída deste modelo foi comparada com os dados observados de uma torre micrometeorológica instalada na Ilha Deception, arquipélago das Shetland do Sul, Antártica. O presente trabalho tem como objetivo avaliar o desempenho do modelo WRF no 
comportamento da temperatura do ar e da pressão atmosférica, devido à passagem de uma frente fria na Ilha Deception, arquipélago das Shetland do Sul, Antártica.

\section{MATERIAIS E MÉTODOS}

Os dados utilizados neste trabalho fazem parte do projeto INTERCEPTION (Interações entre o Oceano, zona Costeira e Atmosfera em microescala na Ilha Deception, arquipélago das Shetland do Sul, Antártica). Os mesmos foram coletados da torre micrometeorológica que foi instalada na Ilha Deception (62 $57^{\prime}$ de latitude Sul e $60^{\circ} 38^{\prime}$ de longitude Oeste), no período de 17 a 25 de março de2013. Fez-se análise também das imagens do satélite GOES-12 fornecidas pelo CPTEC (Centro de Previsão de Tempo e Estudos Climáticos). Neste trabalho foi escolhido o dia 20 de março de 2013 para realizar as análises, pois neste dia ocorreu a passagem de uma frente fria.

\section{RESULTADOS E DISCUSÕES}

A temperatura observada no início do dia 20 fica em torno dos $3,5^{\circ} \mathrm{C}$, a partir das 08:00 UTC (Tempo Universal Coordenado) a mesma sofre um aumento passando de 3 a $5^{\circ} \mathrm{C}$ (Figura 2 (a)). Esse aumento ocorre devido à presença da frente fria (Figura 1 (a)), pois segundo Mattos (1987), há uma elevação na temperatura do ar com a chegada deste sistema meteorológico. A partir das 11:00 UTC, observa-se que a temperatura do ar diminui até o final do dia, pois a partir deste horário a frente fria começa a se afastar da Ilha Deception e com isso ocorre o ingresso de um sistema de alta pressão (massa de ar frio). A simulação obtida pelo modelo WRF em relação à temperatura, em geral apresentou resultados razoáveis (Figura 2 (a)). Os resultados encontrados referentes à temperatura, mostraram que o WRF teve dificuldade em reproduzir a nebulosidade causada pela frente fria. Porém a partir das 21:00 UTC, quando não há mais influência da frente fria, o modelo apresenta bom resultado pois a temperatura simulada e a observada apresentam uma diferença pequena. E às 24:00 UTC esta diferença é ainda menor, ficando em torno de apenas $0,7^{\circ} \mathrm{C}$. Em relação à pressão atmosférica, verifica-se que com a aproximação da frente fria a mesma diminui passando de 982 para $967 \mathrm{hPa}$, aproximadamente (Figura 2 (b)). Esta queda na pressão atmosférica concorda com os estudos de Rodrigues et al. (2004), que observaram que a passagem, formação ou intensificação deste fenômeno faz com que a pressão atmosfera 
diminua. A partir das17:00 UTC, com a dissipação da frente fria e consequentemente o avanço do sistema de alta pressão sobre a Ilha Deception, nota-se que esta variável meteorológica sofre um aumento. A simulação do modelo WRF para a pressão atmosfera obteve bom resultado, pois o modelo seguiu a tendência em praticamente todo o dia estudado, com exceção do período entre às 17:00 e 20:00 UTC.

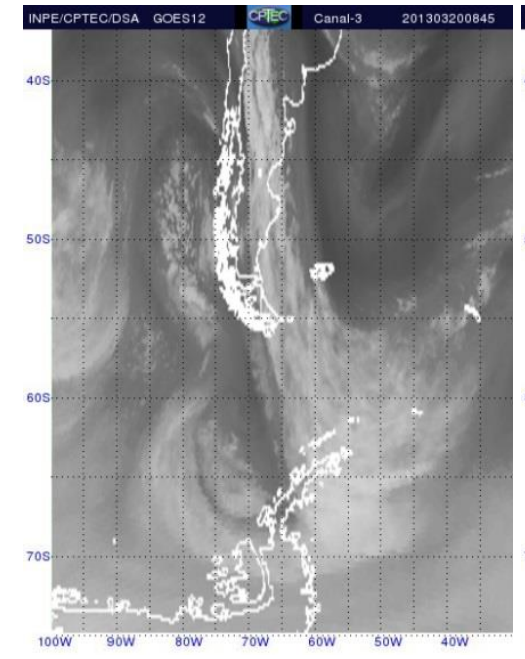

(a)

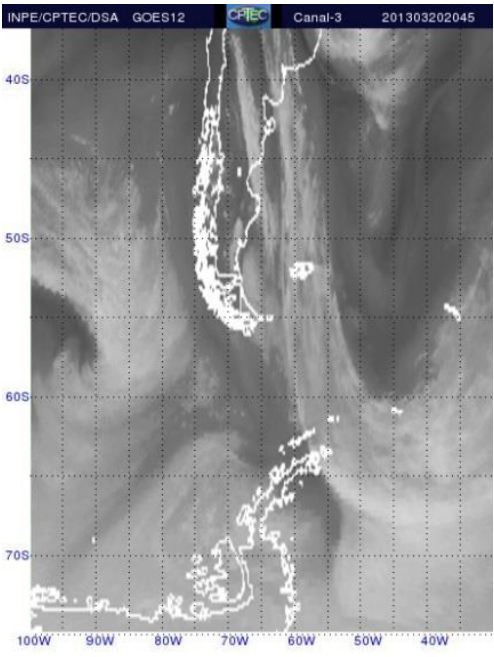

(b)

Figura 1: Imagens do satélite GOES-12 referente ao dia 20 de março de 2013, com a influência de uma frente fria (a) e sem a influência deste sitema (b) na Ilha Deception.

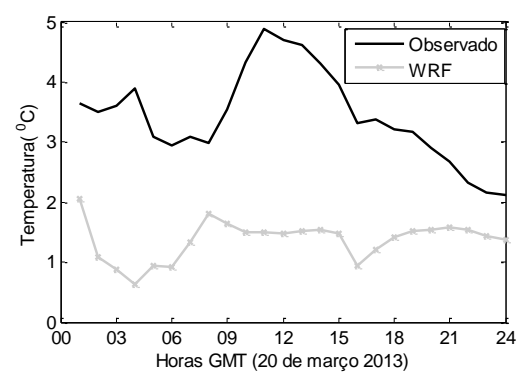

(a)

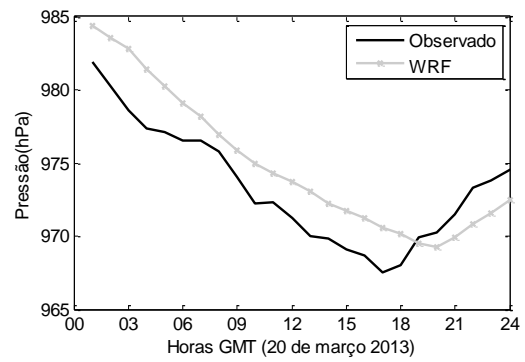

(b)

Figura 2: Temperatura do ar (a) e pressão atmosférica (b) observada e simulada pelo modelo WRF referente ao dia 20 de março de 2013 para a região da Ilha Deception

\section{CONCLUSÃO}

A pressão atmosférica foi mais bem reproduzida pelo modelo, isso se deve ao fato desta variável ter menor variabilidade em pequenas escalas de tempo e, portanto, mais 
dependente dos padrões meteorológicos de grande escala, passados ao WRF. Esse comportamento da pressão atmosférica consiste com alguns trabalhos como os de Hines et al. (2009).

\section{REFERÊNCIAS BIBLIOGRÁFICAS}

HINES, K. M., and D. H. BROMWICH. Development and testing of Polar WRF. Part I: Greenland Ice Sheet meteorology. Monthly Weather. v.136, p. 1971-1989.

MATTOS, L. F. O papel de deformação horizontal na frontogênese na região sul Brasileira. 1987. 118 f. Dissertação. (Mestrado em Meteorologia) - Instituto Nacional de Pesquisas Espaciais, São José dos Campos, 1987.

RODRIGUES, M. L. G., FRANCO, D., SUGAHARA, S. Climatologia de frentes frias no litoral de Santa Catarina. Revista Brasileira de Geofísica, v. 22, n. 2, p. 135 - 151, 2004. 